\title{
Erratum
}

Psychopharmacology (1992) 106:497-501

\section{Effects of zolpidem and flunitrazepam on nocturnal sleep of women subjectively complaining of insomnia}

\author{
A.C. Declerck ${ }^{1}$, F. Ruwe ${ }^{1}$, J.F. O'Hanlon ${ }^{2}$, and A. Wauquier ${ }^{3}$ \\ ${ }^{1}$ Epilepsy Center Kempenhaeghe, Department of EEG and Clinical Neurophysiology, NL-Heeze, The Netherlands \\ ${ }^{2}$ University of Maastricht, Institute for Drugs, Safety and Behavior, NL-Maastricht, The Netherlands \\ ${ }^{3}$ Medical College of Ohio, Department of Neurology, P.O. Box 10008 , Toledo, OH 43699, USA
}

The list of authors should have been as follows:

A.C. Declerck ${ }^{1}$, F. Ruwe ${ }^{1}$, J.F. O'Hanlon ${ }^{2}$, A. Vermeeren ${ }^{2}$, and A. Wauquier ${ }^{3}$ 